\title{
Mimicking Biosintering: The Identification of Highly Condensed Surfaces in Bioinspired Silica Materials
}

\author{
Joseph R. H. Manning, Brant Walkley, John L. Provis, and Siddharth V. Patwardhan*
}

Cite This: Langmuir 2021, 37, 561-568

Read Online

ABSTRACT: Interfacial interactions between inorganic surfaces and organic additives are vital to develop new complex nanomaterials. Learning from biosilica materials, composite nanostructures have been developed, which exploit the strength and directionality of specific polyamine additive-silica surface interactions. Previous interpretations of these interactions are almost universally based on interfacial charge matching and/or hydrogen bonding. In this study, we analyzed the surface chemistry of bioinspired silica (BIS) materials using solid-state nuclear magnetic resonance (NMR) spectroscopy as a function of the organic additive concentration.

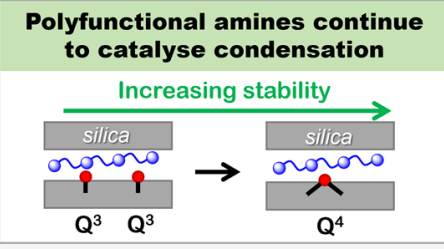
We found significant additional association between the additives and fully condensed $\left(\mathrm{Q}^{4}\right)$ silicon species compared to industrial silica materials, leading to more overall $\mathrm{Q}^{4}$ concentration and higher hydrothermal stability, despite BIS having a shorter synthesis time. We posit that the polyfunctionality and catalytic activity of additives in the BIS synthesis lead to both of these surface phenomena, contrasting previous studies on monofunctional surfactants used in most other artificial templated silica syntheses. From this, we propose that additive polyfunctionality can be used to generate tailored artificial surfaces in situ and provide insights into the process of biosintering in biosilica systems, highlighting the need for more in-depth simulations on interfacial interactions at silica surfaces.

\section{INTRODUCTION}

Understanding the interactions of small organic molecules with inorganic surfaces is key to controlling the formation and behavior of both biological and artificial nanomaterials. Protein-mediated synthesis of nanomaterials with specific shape and function is common in nature, creating nanomaterials such as hydroxyapatite in bone, ${ }^{1}$ biosilica as spicules in sponges and frustules in diatoms, ${ }^{2,3}$ and magnetite crystals in some bacteria. ${ }^{4}$ In vitro, the activity of these biomolecules has been widely studied for material synthesis, leading to the biomimetic synthesis of inorganic chalcogenides, ${ }^{5}$ metals, ${ }^{6,7}$ and even carbon nanotubes, ${ }^{8}$ with the structural properties of each determined by the specific interaction between the biomolecules and inorganic constituents.

In order to take advantage of these interactions, the use of organic additives or templates has been studied extensively for several fully artificial or biologically inspired templated material systems. Taking the case of amorphous silica (a technologically important material with US\$4 billion per annum market), surfactant molecules have been widely investigated to direct long-range, ordered porosity in the materials. ${ }^{10,11}$ Separately, combining the mild and sustainable synthesis conditions of natural silica with the scalability of industrial silica, ${ }^{12}$ "bioinspired silica" (BIS) materials have been synthesized using a variety of small molecules or polymers with biomolecule-like moieties to direct their growth. ${ }^{13-15}$

Given the central role of interfacial processes in structure direction, surface interactions have been studied widely, usually using either solid-state magic angle spinning (MAS) nuclear magnetic resonance (NMR) spectroscopy ${ }^{16-18}$ or molecular dynamics simulations. ${ }^{19-21}$ For artificial silicas, e.g., surfactanttemplated MCM-41 and related materials, NMR is useful to elucidate the specific organic silica binding in solution that leads to a different surface chemistry from acidic or basic pathways. ${ }^{22}$ Further, NMR has also been used to study the chemistry of surfactant templates without permanent charges to detect the nature of template-silica interactions during synthesis. $^{23,24}$ Similarly, for BIS and biomimetic silica materials, there have been previous investigations into how the chemistry of the additive (charged vs uncharged) affects both polymerization and solid silica condensation degree. ${ }^{25-27}$

In biosilica materials, however, investigation into interfacial interactions has long been hampered by the low natural abundance of NMR-active ${ }^{29} \mathrm{Si},{ }^{13} \mathrm{C}$, and ${ }^{15} \mathrm{~N}$ in the inorganic and organic phases. ${ }^{28}$ Accordingly, several studies have focused on analyzing the organic phase themselves to determine the impact of confinement within a silica matrix. ${ }^{29,30}$ To overcome this limitation, several researchers have studied isotopic labeling of the biomolecules ${ }^{31}$ and of diatoms themselves, ${ }^{28}$ enabling more direct investigations of biosilica materials. Similarly, proxy studies have been carried out using organic compounds like isotopically labeled choline ${ }^{26}$ or single amino

Received: November 12, 2020

Revised: December 8, 2020

Published: December 29, 2020 
acids $^{32}$ adsorbed onto artificial silicas and signal amplification using dynamic nuclear polarization ${ }^{33}$ or REDOR $^{28}$ NMR in conjunction with biomolecules to probe chemistry at the interface.

In the case of BIS, use of amine-based polymers as additives rather than neutral tertiary amine-based counterparts (or no organic component at all) was found to both promote synthesis of silica and lead to a more highly condensed material. $^{25}$ This "extra" polymerization was attributed to the established catalytic effect of polyamines on silica polymerization, ${ }^{13}$ signifying that bioinspired additives catalyze both the early stages of silica growth and also its coagulation into larger agglomerates. In artificial templated silicas, ${ }^{1} \mathrm{H}-{ }^{29} \mathrm{Si}$ crosspolarization (CP) MAS NMR, where ${ }^{29} \mathrm{Si}$ signals were amplified according to the proximity of protons, has enabled more in-depth studies, identifying different template-silanol interactions for samples produced at high and low $\mathrm{pH}$ values. ${ }^{22}$

Similar phenomena have been observed during analysis of biomolecule-silica systems as a function of adsorbed water. $^{26,34}$ In these studies, biomolecule surface hydrogen bonding was abundant only at solvated surfaces, whereas charge-matching ammonia-silica interactions were highly prevalent in fully dry materials. This agrees with simulations of fully solvated silicas too, where the nature of bonding has been shown to be a function of surface ionization, hence pH. ${ }^{19,35}$ Few classical simulation studies indicated that there would be significant hydrogen bonding between biomolecules and fully condensed siloxane bonds. One notable case is the simulated adsorption of ammonium-based surfactants onto clay materials with no exposed silanol functionality; ${ }^{36,37}$ hydrogen bonding of ammonium headgroups into $Q^{4}$ clusters was detected, indicating an interaction strength of up to $50 \mathrm{~kJ} /$ mol. ${ }^{37}$ Despite these predictions, no equivalent interactions have been detected on surfaces containing free silanol and siloxane $\mathrm{Q}^{3}$ species, presumably because of the increased strength of charge-matching interactions (ca. $250 \mathrm{~kJ} / \mathrm{mol}$ ). ${ }^{35}$ Conversely, $\mathrm{ab}$ initio simulations ${ }^{34}$ and NMR investigations of isotopically enriched biological silicas ${ }^{28}$ have identified the possibility of a biomolecule-siloxane silica interaction.

However, experimental studies are hindered by the difficulty of knowing and controlling the location of biomolecules within silica: the distribution of biomolecule structures and adsorption states present within biosilicas prevents clear quantitative characterization, ${ }^{26}$ necessitating the use of model systems. $^{27}$ Recently, we developed a method of postsynthetically modifying BIS materials to control the elution of some or all of the additive molecules from within the composite material by changing the acidity of a BIS suspension, ${ }^{35}$ enabling investigation of silica surface chemistry after removal of the additive without surface dehydration associated with prior methods, that is, calcination. Notably, both the BIS synthesis technique and later elution produced consistent amounts of additives within the silica material, indicating the extent of elution is a function of silica charge and therefore that the most loosely-held additives are removed first. We believe that this unprecedented control over the silica-organic interface can be a powerful tool to help characterize interfacial interactions in hybrid silica materials.

In this study, we combined the previously developed acid elution technique with solid-state NMR experiments probing ${ }^{1} \mathrm{H}$ and ${ }^{29} \mathrm{Si}$ to resolve the local structure and surface chemistry of this BIS at different levels of activation (i.e., additive removal), assessing how surface bonding is affected by the additive's initial incorporation and subsequent removal. By comparing this against amine-free industrially precipitated silica (IPS) and IPS, which has been exposed to additive, we show the lasting impact additive has on silica polymerization and how this may relate to other nanocomposite silica materials.

\section{EXPERIMENTAL SECTION}

Silica Synthesis and Modification. Silica was synthesized according to methods previously published by the authors. ${ }^{35,38}$ Briefly, solutions of sodium silicate pentahydrate (Fisher Scientific, technical grade) and pentaethylenehexamine (PEHA; Sigma-Aldrich, technical grade) were separately prepared corresponding to final reaction concentrations of $30 \mathrm{mM}$ each of $\mathrm{Si}$ and $\mathrm{N}$. These were then mixed, neutralized in a single step using $1 \mathrm{M} \mathrm{HCl}$ (Fisher scientific, stabilized), and allowed to react for 5 min under stirring.

After $5 \mathrm{~min}, 1 \mathrm{M} \mathrm{HCl}$ was further added to the silica coagulum to reduce the $\mathrm{pH}$ from 7 to either 5 or 2 . After the $\mathrm{pH}$ had subsequently stabilized (ca. 1 min unless otherwise noted), the materials were isolated by centrifugation at $5000 \mathrm{~g}$ for $15 \mathrm{~min}$. The supernatant was then decanted, and this centrifugation procedure was repeated twice using deionized water to wash the samples of any salts and unreacted reagents. After the last wash, the supernatant was decanted, and the silica was allowed to dry in an oven at $80{ }^{\circ} \mathrm{C}$ overnight.

For the IPS samples, $100 \mathrm{mg}$ of premade silica (Grace, Syloid AL-1 FP grade) was suspended in $100 \mathrm{~mL}$ deionized water. The samples were titrated using $1 \mathrm{M} \mathrm{HCl}$ and $2 \mathrm{M} \mathrm{NaOH}$ (prepared from sodium hydroxide pellets, Fisher Scientific, analytical grade) to the same $\mathrm{pH}$ as for the BIS materials. Because of the low initial electrolyte concentration, the $\mathrm{pH}$ was allowed to equilibrate overnight before separation, followed by washing and drying as described above.

Premade IPS was also exposed to PEHA to assess any impact the additive has on the surface chemistry of premade silica. This was performed at two concentrations; one in which the additive concentration was approximately equal to that used in the BIS synthesis procedure and the other in which the additive concentration was significantly higher. For the lower concentration, $100 \mathrm{mg}$ of IPS was added to $95 \mathrm{~mL}$ of $5 \mathrm{mM}$ PEHA solution (corresponding to 30 $\mathrm{mM}$ dissolved nitrogen, as before). This suspension was then neutralized with $1 \mathrm{~N} \mathrm{H}_{2} \mathrm{SO}_{4}$, and the final volume made up to 100 $\mathrm{mL}$. The higher concentration was prepared by suspending $100 \mathrm{mg}$ of IPS in $0.5 \mathrm{~mL}$ of $250 \mathrm{mM}$ PEHA solution, which was then neutralized as before and made up to a total volume of $2 \mathrm{~mL}$. Solutions were agitated for $1 \mathrm{~h}$ using magnetic stirrer bars before being left to stand for a further $18 \mathrm{~h}$ at an ambient temperature $\left(\mathrm{ca} .20^{\circ} \mathrm{C}\right.$ ) and isolated as described for BIS. For comparison, as-made BIS samples containing PEHA were also aged overnight, and $\mathrm{CHN}$ experiments were performed on these "aged-BIS" samples as described previously (see ref 35).

Solid-State NMR Experiments. Solid-state single pulse ${ }^{29} \mathrm{Si}$ MAS NMR and ${ }^{1} \mathrm{H}-{ }^{29} \mathrm{Si} C P$ MAS NMR spectra were acquired on a Bruker AVANCE III HD 500 spectrometer at $11.7 \mathrm{~T}\left(B_{0}\right)$ using a $4.0 \mathrm{~mm}$ dual resonance CP/MAS probe, yielding a Larmor frequency of 99.35 $\mathrm{MHz} .{ }^{29} \mathrm{Si}$ MAS NMR spectra were acquired using a $4 \mu$ s nonselective $(\pi / 2)$ excitation pulse, a measured $90 \mathrm{~s}$ relaxation delay, a total of 256 scans, and spinning at $12.5 \mathrm{kHz} .{ }^{1} \mathrm{H}-{ }^{29} \mathrm{Si}$ CP MAS NMR experiments were performed using the same instrument with a spinning frequency of $12.5 \mathrm{kHz}, \mathrm{a}^{29} \mathrm{Si}$ nonselective $(\pi / 2)$ pulse width of $4.0 \mu \mathrm{s}$, an initial ${ }^{1} \mathrm{H}$ nonselective $(\pi / 2)$ pulse width of $2.5 \mu \mathrm{s}$, a recycle delay of $3 \mathrm{~s}$, and Hartmann-Hahn contact periods of $2 \mathrm{~ms}$. A nominal ${ }^{1} \mathrm{H}$ decoupling field strength of $80 \mathrm{kHz}$ was employed during acquisition and 1456 scans were collected per experiment. ${ }^{1} \mathrm{H}$ MAS NMR spectra were acquired using a $2.5 \mu$ s nonselective $(\pi / 2)$ excitation pulse, a single scan, and spinning at $12.5 \mathrm{kHz}$. All ${ }^{29} \mathrm{Si}$ spectra were referenced to tetramethylsilane (TMS) at $0 \mathrm{ppm}$, and all ${ }^{1} \mathrm{H}$ spectra were referenced to liquid $\mathrm{H}_{2} \mathrm{O}$ at $4.7 \mathrm{ppm}$. Gaussian peak profiles were used to deconvolute the ${ }^{29} \mathrm{Si}$ MAS NMR and ${ }^{1} \mathrm{H}-{ }^{29} \mathrm{Si}$ CP MAS NMR spectra. ${ }^{39}$ The minimum possible number of peaks were fitted, and the chemical shift $\left(\delta_{\text {iso }}\right)$ and peak full width at half maximum (fwhm) 
of each resonance were required to be consistent in both the ${ }^{29} \mathrm{Si}$ MAS NMR and ${ }^{1} \mathrm{H}-{ }^{29} \mathrm{Si}$ CP MAS NMR spectra. When fitting the data, $\delta_{\text {iso }}$ and fwhm were held constant for each site within the same sample (i.e., only peak intensity was allowed to vary). NMR parameters for all spectra are shown in Tables S1-S4 for BIS, aged BIS, IPS, and modified IPS respectively.

\section{RESULTS AND DISCUSSION}

${ }^{29}$ Si MAS NMR. BIS was synthesized by room-temperature precipitation at $\mathrm{pH} 7$ using PEHA as a bioinspired additive. ${ }^{38}$ These and samples of IPS were acidified to change the surface charge and hence PEHA surface concentration in the case of BIS (see Supporting Information and ref 35 for details). Samples were therefore titrated to $\mathrm{pH} 7$ (corresponding to asmade BIS), $\mathrm{pH} 5$ (partial PEHA removal), and $\mathrm{pH} 2$ (full PEHA removal). These were then analyzed by ${ }^{29} \mathrm{Si}$ MAS NMR to study how PEHA removal affected the silica structure itself (Figure 1, below). ${ }^{29} \mathrm{Si}$ MAS NMR enables distinction between
A
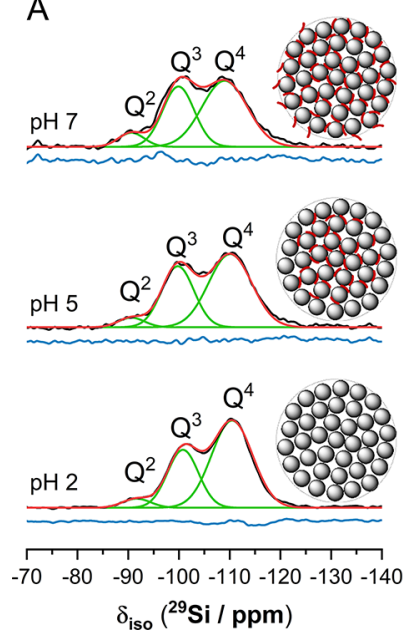
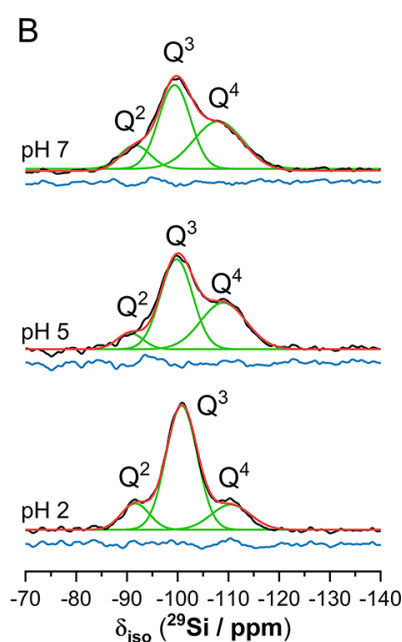

Figure 1. ${ }^{29} \mathrm{Si}$ single-pulse MAS NMR spectra for (A) BIS and (B) IPS washed at $\mathrm{pH} 7$ (top), 5 (middle), and 2 (bottom) and associated deconvolutions. Overlaid are representative schemes (adapted from ref 31) of BIS: silica primary particles (gray circles) containing PEHA molecules (red lines) at as-made concentration (top), partially extracted (middle), and fully extracted (bottom). The NMR spectra shown are for the original data (black), individual resonance contributions (green), fitted sum of individual contributions (red), and residual (blue).

fully saturated silicon centers $\left(\mathrm{Q}^{4}\right.$ at ca. $\left.\delta_{\text {iso }}=-110 \mathrm{ppm}\right)$ with singly hydroxylated $\left(\mathrm{Q}^{3}\right.$, ca. $\left.\delta_{\text {iso }}=-100 \mathrm{ppm}\right)$ and doubly hydroxylated $\left(\mathrm{Q}^{2}\right.$, ca. $\left.\delta_{\text {iso }}=-90 \mathrm{ppm}\right)$ Si centers ${ }^{40}$ and hence quantification of their relative abundance in the material. From this, the degree of polymerization in BIS was observed to be higher than that in industrial silica (Table 1). This is unexpected, as polymerization of silica from $\mathrm{Q}^{3}$ to $\mathrm{Q}^{4}$ is generally considered to occur through syneresis ${ }^{41}$ - the slow condensation of silica to expel water from the frameworkwhich should be more prevalent in the industrial silica material because of its significantly longer reaction times $(2-3 \mathrm{~h}$ vs 5 $\min )^{12}$ and similar micron-scale aggregate sizes compared to BIS. $^{35,42}$

Upon modification of $\mathrm{pH}$, the surface $\mathrm{Si}$ speciation of IPS changed slightly to include fewer $\mathrm{Q}^{4}$ sites (from $55 \%$ relative abundance at $\mathrm{pH} 7$ to $48 \%$ relative abundance at $\mathrm{pH} 2$ ) and correspondingly more $\mathrm{Q}^{3}$ and $\mathrm{Q}^{2}$ sites (Figure 2). This is in

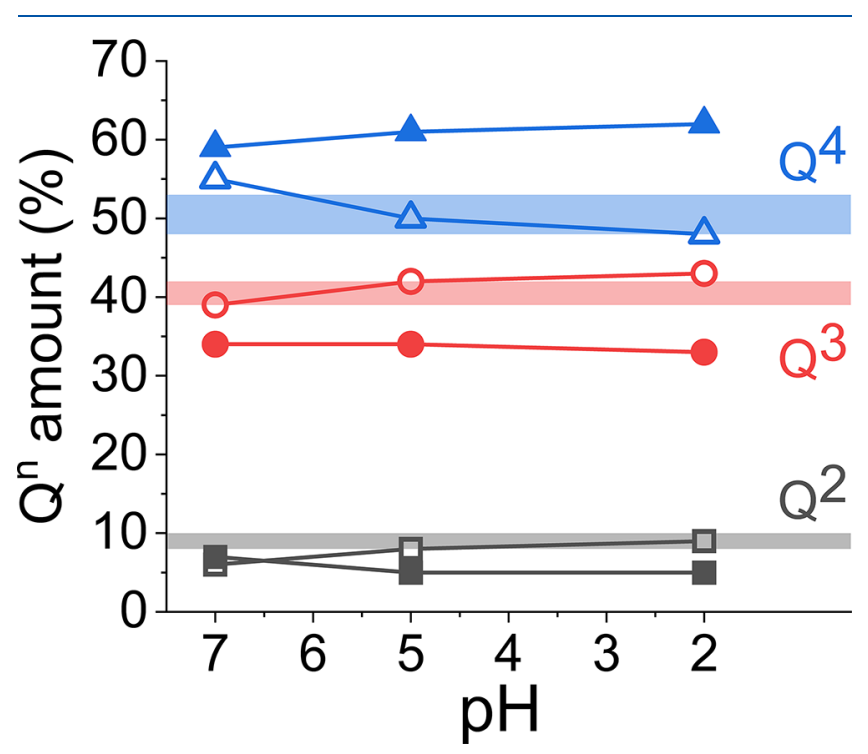

Figure 2. Relative abundance of $\mathrm{Si} \mathrm{Q}^{n}$ species (determined from the ${ }^{29} \mathrm{Si}$ single-pulse MAS NMR spectral deconvolutions) against extraction $\mathrm{pH}$ for IPS (open shapes) and BIS (filled) silica materials (with greater degree of extraction at lower $\mathrm{pH}$ ). Overlaid bars are equivalent relative abundance for PEHA-modified IPS materials. Black squares represent $Q^{2}$ species, red circles represent $Q^{3}$ species, and blue triangles represent $Q^{4}$ species.

good agreement with previous studies on the acid treatment of precipitated silicas, which found an increase in $\mathrm{Q}^{3}$ relative abundance of up to $10 \%$ under similar conditions. ${ }^{43}$ For BIS, such $\mathrm{pH}$-based changes were not seen $\left(\mathrm{Q}^{4}\right.$ sites remained at approximately $60 \%$ relative abundance across all $\mathrm{pH}$ values).

PEHA has been shown to be effective at "passivating" silica surfaces to prevent dissolution in undersaturated Si solutions. ${ }^{44}$ Therefore, IPS modification with PEHA was attempted to observe its effect on the surface chemistry of premade silica and determine if the difference in measured $Q^{n}$ ratios resulted from the presence of PEHA in solution or was intrinsic to the BIS materials. To ensure direct comparison between modified

Table 1. Comparison of Relative Peak Integral Areas for Silicon Species within IPS and BIS Materials against pH for Both Single-Pulse ${ }^{29} \mathrm{Si}$ MAS NMR and ${ }^{1} \mathrm{H}-{ }^{29} \mathrm{Si}$ CP MAS NMR Data ${ }^{a}$

\begin{tabular}{|c|c|c|c|c|c|c|c|c|c|c|c|c|c|c|}
\hline \multirow[b]{2}{*}{ relative peak area (\%) } & \multicolumn{2}{|c|}{$\underset{\text { precipitated }}{\mathrm{pH} \mathrm{7-}}$} & \multicolumn{2}{|c|}{$\underset{\text { bioinspired }}{\mathrm{pH} \mathrm{7-}}$} & \multicolumn{2}{|c|}{$\begin{array}{c}\mathrm{pH} \text { 7-bioinspired } \\
(\text { aged 24 h) }\end{array}$} & \multicolumn{2}{|c|}{$\underset{\text { precipitated }}{\mathrm{pH} \mathrm{5-}}$} & \multicolumn{2}{|c|}{$\underset{\text { bioinspired }}{\mathrm{pH} \mathrm{5-}}$} & \multicolumn{2}{|c|}{$\underset{\text { precipitated }}{\mathrm{pH} \mathrm{2-}}$} & \multicolumn{2}{|c|}{$\underset{\text { bioinspired }}{\mathrm{pH} \mathrm{2-}}$} \\
\hline & ${ }^{29} \mathrm{Si}$ & ${ }^{1} \mathrm{H}-{ }^{29} \mathrm{Si}$ & ${ }^{29} \mathrm{Si}$ & ${ }^{1} \mathrm{H}-{ }^{29} \mathrm{Si}$ & ${ }^{29} \mathrm{Si}$ & ${ }^{1} \mathrm{H}-{ }^{29} \mathrm{Si}$ & ${ }^{29} \mathrm{Si}$ & ${ }^{1} \mathrm{H}-{ }^{29} \mathrm{Si}$ & ${ }^{29} \mathrm{Si}$ & ${ }^{1} \mathrm{H}-{ }^{29} \mathrm{Si}$ & ${ }^{29} \mathrm{Si}$ & ${ }^{1} \mathrm{H}-{ }^{29} \mathrm{Si}$ & ${ }^{29} \mathrm{Si}$ & ${ }^{1} \mathrm{H}-{ }^{29} \mathrm{Si}$ \\
\hline$Q^{2}$ & 6 & 14 & 7 & 12 & $4 \pm 0$ & $12 \pm 1$ & 8 & 20 & 5 & 8 & 9 & 20 & 5 & 13 \\
\hline$Q^{3}$ & 39 & 77 & 34 & 47 & $32 \pm 1$ & $65 \pm 1$ & 42 & 71 & 34 & 53 & 43 & 72 & 33 & 69 \\
\hline$Q^{4}$ & 55 & 9 & 59 & 41 & $64 \pm 1$ & $17 \pm 1$ & 50 & 9 & 61 & 39 & 48 & 9 & 62 & 18 \\
\hline
\end{tabular}

${ }^{a}$ Error bars are one standard deviation around the mean $(n=3$ silica samples), rounded to the nearest integer. 
IPS and BIS, more BIS samples were synthesized and aged at ca. $\mathrm{pH} 7$ for a similar time (i.e., untreated for $24 \mathrm{~h}$ ) prior to isolation.

After exposing IPS to PEHA, the relative $Q^{4}$ concentration was again slightly lowered, compared to the $\mathrm{pH} 7$ sample (from 59 to 48 or $53 \%$ relative abundance at low and high [PEHA], respectively, see Table S3), with concurrent increases in $\mathrm{Q}^{3}$ and $\mathrm{Q}^{2}$ prevalence. This runs counter to the stabilization observed in the previous study, although the effect could be due to higher overall $[\mathrm{Si}$ ] (ca. $30 \mathrm{mM}$ herein, cf. $1 \mathrm{mM}$ in ref 44) or higher ionic strength during IPS modification (see Table S5). Regardless, it is clear that addition of PEHA to silica materials postsynthesis did not replicate the high and sustained condensation states observed in BIS. A similar behavior was not observed during aging of BIS samples (Table S2), wherein $\mathrm{Q}^{3}$ prevalence remained the same $(32 \pm 1 \%$, cf. $34 \%$ for unaged BIS) and $\mathrm{Q}^{4}$ prevalence increased slightly at the expense of $Q^{2}$ species $(64 \pm 1$ and $4 \pm 0 \%$ cf. 59 and $7 \%$ for unaged BIS). Despite the increased silica condensation, aged BIS samples exhibited an unexpected decrease in PEHA content-from 0.64 to $0.12 \mathrm{mmol} / \mathrm{g}$ (ca. $80 \%$ removal, see Table S6) - indicative of significant leaching of the additive.

Overall, the ${ }^{29} \mathrm{Si}$ MAS NMR data indicate that BIS was in fact more stable than IPS. This is significant because even after removal of the PEHA by elution to $\mathrm{pH} 2$ or $24 \mathrm{~h}$ of aging, BIS maintained a high $\mathrm{Q}^{4}$ concentration, indicating that the structures have a higher hydrothermal stability even after purification. ${ }^{45,46}$ This provides the first direct comparison of BIS hydrothermal stability against industrial silicas, showing that the use of bioinspired additives creates more stable materials.

Given that BIS was found to be more condensed than IPS even after PEHA extraction/leaching, we hypothesize that the additive (PEHA) might be causing these effects during the initial synthesis. In order to test this hypothesis, we probed the interaction between silica and the adsorbed additive to determine the localization of PEHA surface interaction and why this causes lower susceptibility to attack by acidic medium even after full PEHA loss.

${ }^{1} \mathrm{H}$ MAS NMR. Initially, ${ }^{1} \mathrm{H}$ MAS NMR data for the three silica materials were gathered to observe any changes to the silanol chemical environment upon addition of PEHA. For IPS, a single well-defined peak was observed at approximately $\delta_{\text {iso }}=$ $5.5 \mathrm{ppm}$ for all samples (Figure 3a), indicating a uniform chemical environment for the silanol species therein (corresponding to water molecules hydrogen bonded to silanol groups). ${ }^{47}$ Introduction of PEHA to IPS led to significant broadening of the ${ }^{1} \mathrm{H}$ MAS NMR resonance as well as peak shifting to higher ppm values (ca. $\delta_{\text {iso }}=6.5 \mathrm{ppm}$, corresponding to previous reports of ammonium hydroxide in silica zeolites, Figure $3 \mathrm{~b}) .{ }^{48}$ Peak broadening was even more pronounced for as-made BIS (Figure 3c), indicating that PEHA encapsulated during synthesis led to a wider range of local Si chemical environments. Upon extraction of PEHA from BIS by lowering the $\mathrm{pH}$ the peak broadening reduced until, at $\mathrm{pH} 2$, a ${ }^{1} \mathrm{H}$ MAS NMR spectrum was observed that exhibited a lineshape similar to that of IPS.

This indicates that, although the quantity of $\mathrm{Si}-\mathrm{OH}$ moieties was different between BIS and IPS at $\mathrm{pH} 2$, the chemical environment in each of those moieties was similar. Furthermore, with regards to the goal of using acid elution of additives as a means of controlling organic localization within a silica matrix, we note that PEHA-modified IPS appears

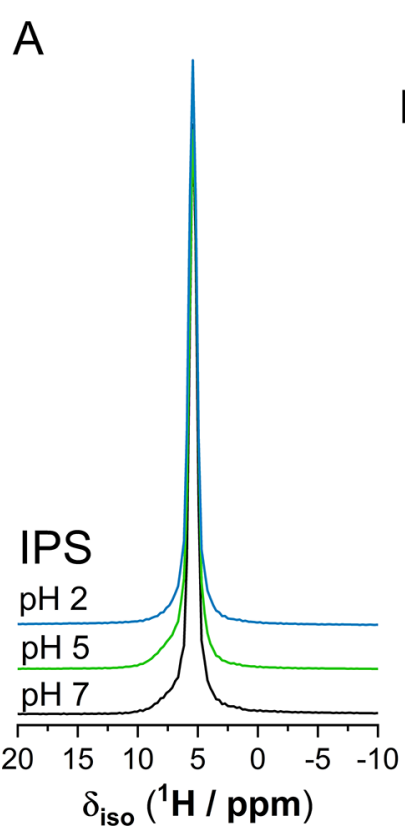

B

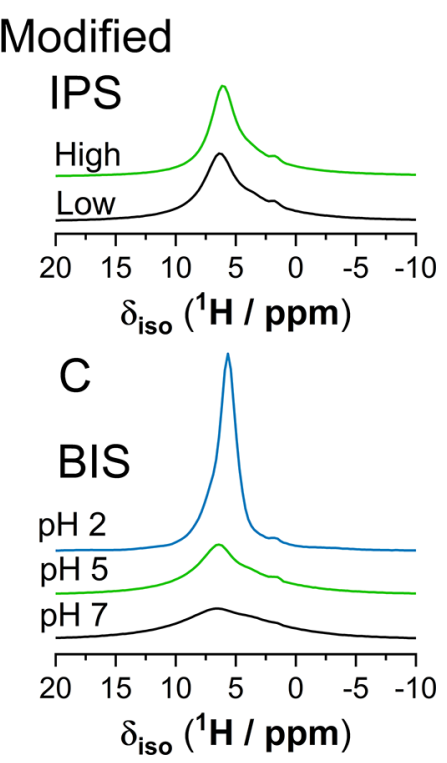

Figure 3. ${ }^{1} \mathrm{H}$ MAS NMR spectra for (a) IPS at $\mathrm{pH} 7$ (black), 5 (green), and 2 (blue), (b) PEHA-modified IPS at low (black) and high (green) PEHA concentration, and (c) BIS at $\mathrm{pH} 7$ (black), 5 (green), and 2 (blue).

qualitatively similar to BIS treated to $\mathrm{pH} 5$, but not as-made ( $\mathrm{pH}$ 7) BIS (Figure 3b,c, respectively). The emergence of more well-defined peaks after partial extraction agrees with the authors' earlier supposition that more loosely held additives are extracted first ${ }^{35}$ and therefore suggests that partial extraction can indeed be used as a tool to ensure uniform organic entrapment within a BIS matrix.

${ }^{1} \mathrm{H}-{ }^{29}$ Si CP MAS NMR. Although both the ${ }^{29} \mathrm{Si}$ and ${ }^{1} \mathrm{H}$ MAS NMR data provide insights into the effect of PEHA on BIS chemistry, no specific details about the PEHA-silica binding were revealed. To better elucidate this, the bonding environment of $\mathrm{Si}$ with its proximate protons was measured using ${ }^{1} \mathrm{H}-{ }^{29} \mathrm{Si} \mathrm{CP}$ MAS NMR. In the absence of any additives, we expect that $Q^{2}$ and $Q^{3}$ Si signals will be amplified as they are covalently connected to hydroxyl groups (hence protons), while $\mathrm{Q}^{4}$ Si resonances will be dampened because of the absence of any protons within close proximity. Indeed, for the IPS, ${ }^{1} \mathrm{H}-{ }^{29} \mathrm{Si}$ CP MAS NMR data exhibited amplified $\mathrm{Q}^{2}$ and $\mathrm{Q}^{3}$ silica signals and suppressed $\mathrm{Q}^{4}$ signals (Tables $1, \mathrm{~S} 2$ and Figure 4) regardless of the treatment $\mathrm{pH}$. For BIS, ${ }^{1} \mathrm{H}-{ }^{29} \mathrm{Si} \mathrm{CP}$ MAS NMR data showed significant differences for all $\mathrm{pH}$ treatments due to the presence (or absence) of PEHA (Figure 4). Compared to the IPS, BIS-containing PEHA ( $\mathrm{pH} 7$ and $\mathrm{pH}$ 5) had relatively large $\mathrm{Q}^{4}$ signals (ca. $40 \%$ cf. $9 \%$ in IPS) and smaller $\mathrm{Q}^{3}$ and $\mathrm{Q}^{2}$ signals in the ${ }^{1} \mathrm{H}-{ }^{29} \mathrm{Si} C \mathrm{CP}$ MAS NMR spectra (Figure 5). However, upon removal of PEHA ( $\mathrm{pH} 2$, or aging for $24 \mathrm{~h}$ ), this effect diminished and the relative amount of $\mathrm{Q}^{2}$ and $\mathrm{Q}^{3}$ signals increased, similar to that of their IPS counterparts. Interestingly, ${ }^{1} \mathrm{H}-{ }^{29} \mathrm{Si} \mathrm{CP}$ MAS NMR data showed that the surface hydroxylation of PEHA-modified IPS differed from that of both unmodified IPS and BIS, with only minor suppression of the $\mathrm{Q}^{3}$ signal to ca. $55 \% \mathrm{cf}, 75 \%$ in IPS and ca. $47 \%$ in BIS (as well as concurrent $\mathrm{Q}^{4}$ amplification, see Figure 5).

The ${ }^{1} \mathrm{H}-{ }^{29} \mathrm{Si} \mathrm{CP}$ MAS NMR data suggest that in addition to creating more $\mathrm{Q}^{4}$ species in BIS, PEHA forms an adduct with 

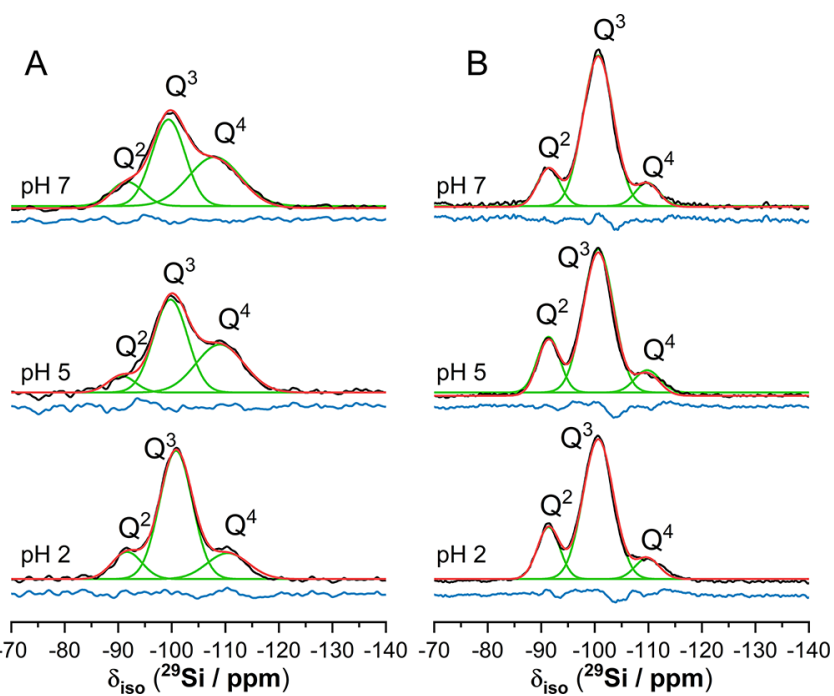

Figure 4. ${ }^{1} \mathrm{H}-{ }^{29} \mathrm{Si}$ CP MAS NMR spectra for (A) BIS and (B) IPS washed at pH 7 (top), 5 (middle), and 2 (bottom) and associated deconvolutions. The original data (black), individual resonance contributions (green), fitted sum of individual contributions (red), and residual (blue) are shown.

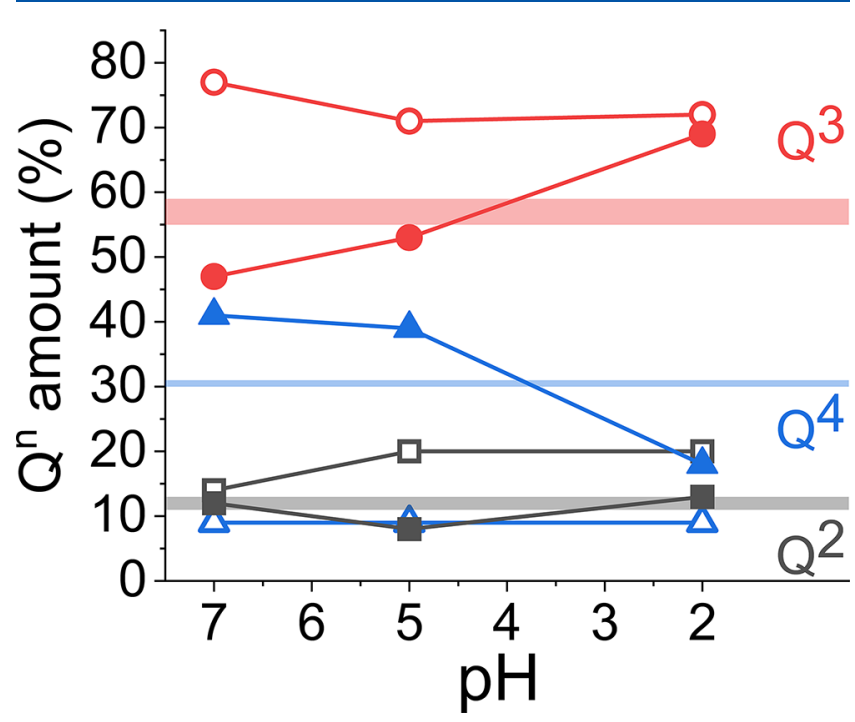

Figure 5. Relative abundance of ${ }^{1} \mathrm{H}$-proximate $\mathrm{Si} \mathrm{Q}^{n}$ species (determined from the ${ }^{1} \mathrm{H}-{ }^{29} \mathrm{Si}$ CP MAS NMR spectra) against extraction $\mathrm{pH}$ for IPS (open shapes) and BIS (filled shapes) silica materials (with a greater degree of extraction at lower $\mathrm{pH}$ ). Overlaid bars are equivalent relative abundance for PEHA-modified IPS materials. Black squares represent $\mathrm{Q}^{2}$ species, red circles represent $\mathrm{Q}^{3}$ species, and blue triangles represent $Q^{4}$ species.

$\mathrm{Q}^{4}$ Si sites in general; $\mathrm{Q}^{4}$ signals were enhanced in both BIS and modified IPS materials. This agrees with the results reported by Folliet et al., which proposed amine- $\mathrm{Q}^{4}$ hydrogen bonding as part of quantum chemical simulations. ${ }^{34}$ However, these findings appear to contradict previous simulations and experimental results for artificial templated silica systems, which show electrostatic or ion-pairing interactions only during surface adsorption of PEHA (or other amine molecules), that is, onto deprotonated $Q^{3}$ Si centers only. $^{27,35,49,50}$ Previous studies of dried silica surfaces have shown secondary interactions with surrounding moieties are possible; ${ }^{26}$ therefore, $\mathrm{PEHA}-\mathrm{Q}^{4}$ adducts may be the result of secondary interactions on (partially) dried BIS surfaces.

However, this explanation for the detected ${ }^{1} \mathrm{H}-\mathrm{Q}^{4}$ adducts cannot explain why the absolute $Q^{4}$ concentration is enhanced in BIS materials compared to either IPS or modified-IPS materials. To explain this, we first note that PEHA has been shown to act as a catalyst in the initial condensation of silicic acid monomers, presumably through proton transfer. This was previously assumed to occur only in the solution phase during synthesis, ${ }^{49,51}$ where PEHA can freely disassociate from any silicate center after condensation due to weaker interaction with the now covalently saturated oxygen atom. Based on our findings, we posit that this catalysis continues after the amine molecule is physically trapped within the silica matrix (analogous to the "embedded" state recently proposed by Montagna et al. $^{27}$ ). In this case, desorption of PEHA after the $\mathrm{Q}^{3}$ sites have been polymerized is hindered, leading to the higher initial ${ }^{1} \mathrm{H}-\mathrm{Q}^{4}$ adduct concentration, which disappears after $24 \mathrm{~h}$.

The varying representation of surface additive silica reactivity is visualized in Figure 6. In the absence of additives, silica condensation is known to occur through charged $\mathrm{SiO}^{-}$ moieties nucleophilically attacking $\mathrm{Si}-\mathrm{OH}$ centers, eventually leading to the elimination of $\mathrm{OH}^{-}(\mathrm{A})$; given the reported $\mathrm{p} K_{\mathrm{a}}$ of 6.8 , these moieties are approximately equally abundant at $\mathrm{pH} 7{ }^{52,53}$ Prior MD results indicate that PEHA attaches to such $\mathrm{SiO}^{-}$surface sites during silica synthesis (B), and that the $\mathrm{SiO}^{-}$density is sufficiently low that PEHA can only "see" one such site. This predisposes us to think that further surface condensation only leads to PEHA dissociation (C) and presumably re-association at a different $Q^{3}$ site. The results we have found, combined with the recently published report by Montagna et al., ${ }^{27}$ indicate that this is not the case. Instead, PEHA interacts with multiple surface sites, facilitated by the embedded configuration (D). These $\mathrm{SiO}^{-}$moieties then polymerize further (E), leading to the unexpected PEHA- $\mathrm{Q}^{4}$ adducts seen in unaged BIS samples. PEHA then slowly leaches away from the surface, bringing the CP MAS results in line with modified IPS, while retaining the highly condensed surface chemistry.

These findings continue a pattern where higher condensation is associated with multifunctional additives only (either biopolymers or artificial compounds). ${ }^{25} \mathrm{Q}^{4}$-template adducts have previously been detected in the cell walls of the diatom Thalassiosira pseudonana ${ }^{28}$ as well as oligo- ${ }^{33}$ and monopeptides $^{32}$ derived from the proteins therein. However, because the vast majority of artificially templated silica materials use monofunctional templates, which would be unable to make secondary interactions of these kinds with their silica surfaces, we conclude that polyfunctionality appears to be the key factor in determining if template- $\mathrm{Q}^{4}$ interactions can occur.

Accordingly, these results provide a useful indication of how template functionality may be employed to tailor surface chemistry. By taking advantage of the polyfunctional (and especially catalytically active) additive compounds, artificially templated silicas with higher degrees of surface condensation and hence hydrothermal stability could be designed without recourse to postsynthetic functionalization or changes to the material recipe itself-a key challenge in current templated silica design. ${ }^{54}$ With regards to biosilica materials, this finding can provide a tentative explanation on a molecular level for complex and hard-to-analyze biological phenomena such as biosintering - the fusing of silica lamella in the core of sponge 


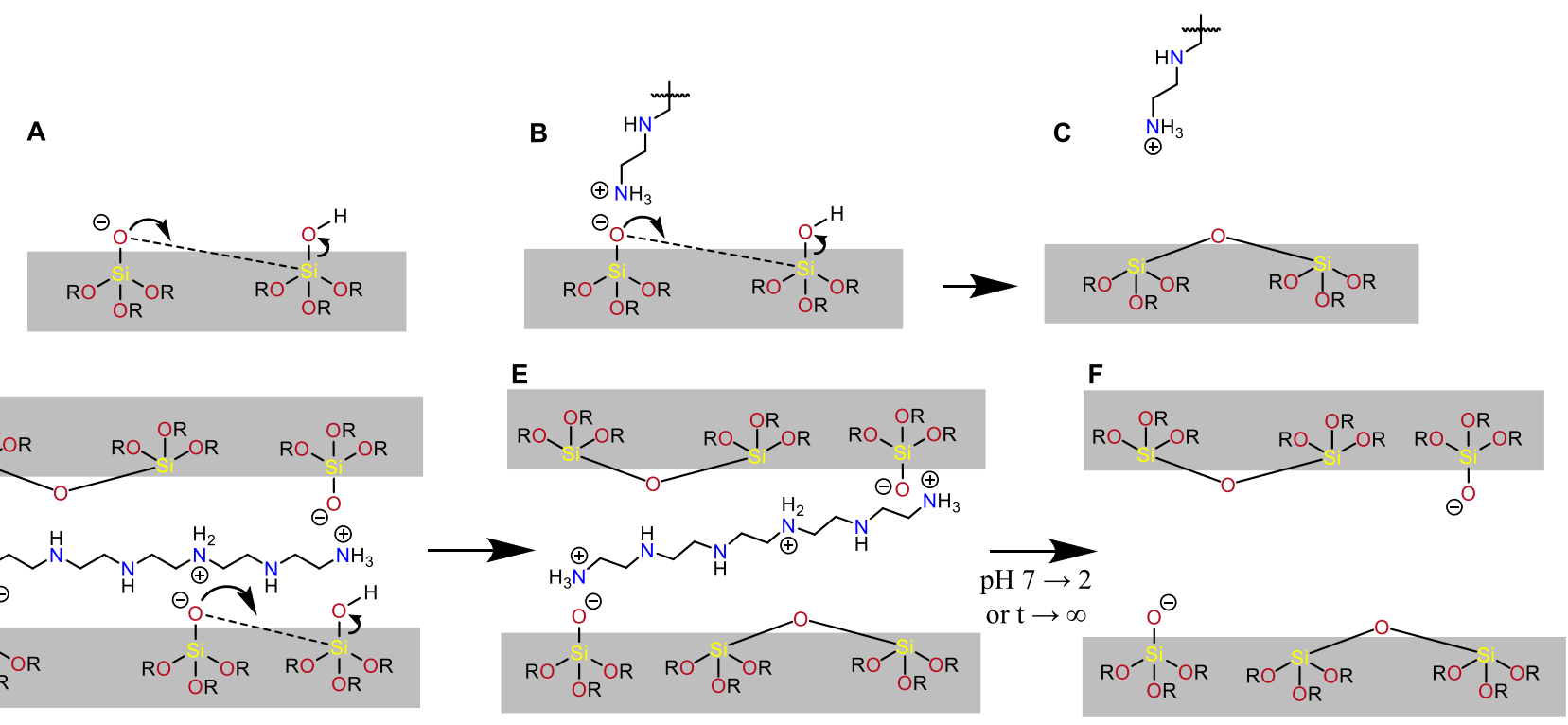

Figure 6. Scheme visualizing potential mechanisms of surface silanol condensation of BIS materials at $\mathrm{pH}$ 7. (A) In the absence of organic additives, $(\mathrm{B}, \mathrm{C})$ at single silica surfaces, wherein the additive can freely desorb after elimination of surface $\mathrm{SiO}^{-}$moiety, and $(\mathrm{D}, \mathrm{E})$ in the "embedded" state, wherein additives remain in close contact with the surface after polymerization of some surface $\mathrm{SiO}^{-}$moieties, before slowly leaching from the material. $\mathrm{OH}^{-}$leaving groups are omitted in each case for clarity.

spicules. ${ }^{55}$ This process has been theorized to occur through continued catalytic activity of silica-depositing proteins trapped within already-formed sponge spicules. ${ }^{56}$ Our findings suggest a potential route to direct investigation of biosintering by highlighting the similarities of BIS materials made with different polyfunctional additives and biosilica and also by showing how the use of BIS enables investigation through modification of the material postsynthetically while preserving the silica surface chemistry. Furthermore, this indicates that BIS materials may be useful as model systems to study biosilica formation. Given the range of different bioinspired template structures, ${ }^{57}$ specific biological motifs or even general physical properties can be replicated and studied in isolation, providing reductionist insights into the more complex biological systems.

Finally, we believe that our results highlight a potentially important difference between current atomistic and ab initio simulations of silica surfaces. Our findings indicate that additive- $\mathrm{Q}^{4}$ interactions, which have been positively identified during quantum chemical simulations but not in forcefieldbased methods, are more prevalent than previously considered, and therefore current atomistic simulations of solvated silica are not enough to fully describe the interfacial chemistry. Further, simulations on partially or fully dewatered surfaces (such as those reported in ref 26) are needed to fully describe the more complex interfacial chemistry present in systems with polyfunctional templates. Future research focusing on solidstate NMR experiments directly probing ${ }^{13} \mathrm{C}$ and ${ }^{15} \mathrm{~N}$ nuclei on isotopically labeled PEHA and other bioinspired additives, as well as experiments probing ${ }^{13} \mathrm{C}-{ }^{29} \mathrm{Si}$ and ${ }^{15} \mathrm{~N}-{ }^{29} \mathrm{Si}$ internuclear distances (e.g., ${ }^{13} \mathrm{C}-{ }^{29} \mathrm{Si}$ and ${ }^{15} \mathrm{~N}-{ }^{29} \mathrm{Si} \mathrm{CP}$, HETCOR, or REDOR MAS NMR) will be vital to further resolve the surface PEHA-silica interactions and PEHA-mediated silica synthesis.

\section{SUMMARY AND CONCLUSIONS}

BIS materials were produced using the additive PEHA and analyzed by solid-state ${ }^{1} \mathrm{H}$ MAS, ${ }^{29} \mathrm{Si}$ MAS, and ${ }^{1} \mathrm{H}-{ }^{29} \mathrm{Si} \mathrm{CP}$ MAS NMR after treatment to a range of different $\mathrm{pH}$ values.
These were then compared against IPS (both treated to equivalent $\mathrm{pH}$ levels and after modification with PEHA), finding significantly higher condensation in the BIS, despite having a lower reaction time, even after modification with the catalytic PEHA template. This signifies that bioinspired synthesis methods can produce more hydrothermally stable silica than current industrial practices, a key property for the materials.

${ }^{1} \mathrm{H}-{ }^{29} \mathrm{Si} \mathrm{CP}$ MAS data showed that the additional $\mathrm{Q}^{4}$ sites associate with the PEHA additive, a phenomenon which has only been previously observed in biomolecule- or polymertemplated silica materials. We propose that these adducts arise because of secondary additive-silica interactions from organic additives in the "embedded" configuration, something which is impossible for more commonly studied monofunctional templates. These results highlight that BIS lies at the intersection between biosilica and artificially templated silica materials (as explained elsewhere ${ }^{58}$ ), providing the advantages of catalytically active templating behavior to artificially templated silica materials while enabling systematic investigation into the more complex interfacial phenomena present in biosilicas.

Separately, our investigations of aged BIS materials show for the first time that the composition of BISs is not constant over time. The loss of additives from within the silica-amine composite over a $24 \mathrm{~h}$ period is highly surprising, especially given the author's pervious demonstration of highly consistent silica compositions after a range of postsynthetic modifications. This therefore necessitates further investigation of the kinetic stability of additive occlusion within BIS materials as a function of additive structure, solution composition, and synthesis conditions.

Overall, these findings are significant, as they demonstrate an as-yet unexploited design space for artificially templated silica materials, wherein the catalytically active additives can be used to stabilize silica surfaces, even after their removal. Finally, this mechanism of surface catalysis by embedded additive compounds provides a potential explanation for the biological 
phenomenon of biosintering in sponge spicules and highlights the overlooked details in current atomistic simulations of templated silica interfaces which are incapable of predicting such reactions.

\section{ASSOCIATED CONTENT}

\section{(s) Supporting Information}

The Supporting Information is available free of charge at https://pubs.acs.org/doi/10.1021/acs.langmuir.0c03261.

NMR peak deconvolution and relative integral area for all samples analyzed, graphs of ${ }^{29} \mathrm{Si}$ MAS, and ${ }^{1} \mathrm{H}-{ }^{29} \mathrm{Si}$ CP MAS NMR spectra of modified IPS and aged BIS samples (including peak deconvolutions), ionic strength for BIS and IPS samples prepared at different $\mathrm{pH}$ conditions, and CHN elemental analysis for aged BIS samples (PDF)

\section{AUTHOR INFORMATION}

\section{Corresponding Author}

Siddharth V. Patwardhan - Department of Chemical and Biological Engineering, The University of Sheffield, Sheffield S1 3JD, U.K.; 이이이.org/0000-0002-4958-8840; Email: s.patwardhan@sheffield.ac.uk

\section{Authors}

Joseph R. H. Manning - Department of Chemical and Biological Engineering, The University of Sheffield, Sheffield S1 3JD, U.K.; Department of Chemical Engineering, The University of Bath, Bath BA2 7AY, U.K.; Department of Chemistry, University College London, London WC1E 6BT, U.K.

Brant Walkley - Department of Chemical and Biological Engineering, The University of Sheffield, Sheffield S1 3JD, U.K.; Department of Materials Science and Engineering, The University of Sheffield, Sheffield S1 3JD, U.K.; i orcid.org/ 0000-0003-1069-1362

John L. Provis - Department of Materials Science and Engineering, The University of Sheffield, Sheffield S1 3JD, U.K.; (1) orcid.org/0000-0003-3372-8922

Complete contact information is available at: https://pubs.acs.org/10.1021/acs.langmuir.0c03261

\section{Notes}

The authors declare no competing financial interest.

\section{ACKNOWLEDGMENTS}

We thank the EPSRC SynBIM project (EP/P006892/1), EPSRC Fellowship (EP/R025983/1), and ERC GROWMOF project (Prof. Tina Düren, ERC grant no. 648283) for their financial support. We thank the departments of Chemistry, Chemical and Biological Engineering, and Materials Science and Engineering at the University of Sheffield for funding and access to facilities. We thank Dr Sandra van Meurs for very insightful discussions and assistance with performing the NMR experiments.

\section{REFERENCES}

(1) Duer, M. J. The Contribution of Solid-State NMR Spectroscopy to Understanding Biomineralization: Atomic and Molecular Structure of Bone. J. Magn. Reson. 2015, 253, 98-110.

(2) Hildebrand, M. Diatoms, Biomineralization Processes, and Genomics. Chem. Rev. 2008, 108, 4855-4874.
(3) Sumper, M.; Kröger, N. Silica Formation in Diatoms: The Function of Long-Chain Polyamines and Silaffins. J. Mater. Chem. 2004, 14, 2059-2065.

(4) Staniland, S. S.; Rawlings, A. E. Crystallizing the Function of the Magnetosome Membrane Mineralization Protein Mms6. Biochem. Soc. Trans. 2016, 44, 883-890.

(5) Dickerson, M. B.; Sandhage, K. H.; Naik, R. R. Protein- and Peptide-Directed Syntheses of Inorganic Materials. Chem. Rev. 2008, $108,4935-4978$

(6) Patwardhan, S. V.; Patwardhan, G.; Perry, C. C. Interactions of Biomolecules with Inorganic Materials: Principles, Applications and Future Prospects. J. Mater. Chem. 2007, 17, 2875-2884.

(7) Coppage, R.; Slocik, J. M.; Sethi, M.; Pacardo, D. B.; Naik, R. R.; Knecht, M. R. Elucidation of Peptide Effects That Control the Activity of Nanoparticles. Angew. Chem., Int. Ed. 2010, 49, 37673770.

(8) Dang, X.; Yi, H.; Ham, M.-H.; Qi, J.; Yun, D. S.; Ladewski, R.; Strano, M. S.; Hammond, P. T.; Belcher, A. M. Virus-Templated SelfAssembled Single-Walled Carbon Nanotubes for Highly Efficient Electron Collection in Photovoltaic Devices. Nat. Nanotechnol. 2011, 6, 377-384.

(9) Grand View Research. Specialty Silica Market Size, Share \& Trend Analysis Report by Product, 2018.

(10) Beck, J. S.; Vartuli, J. C.; Roth, W. J.; Leonowicz, M. E.; Kresge, C. T.; Schmitt, K. D.; Chu, C. T. W.; Olson, D. H.; Sheppard, E. W.; McCullen, S. B.; Higgins, J. B.; Schlenker, J. L. A New Family of Mesoporous Molecular Sieves Prepared with Liquid Crystal Templates. J. Am. Chem. Soc. 1992, 114, 10834-10843.

(11) Gérardin, C.; Reboul, J.; Bonne, M.; Lebeau, B. Ecodesign of Ordered Mesoporous Silica Materials. Chem. Soc. Rev. 2013, 42, $4217-4255$.

(12) Drummond, C.; McCann, R.; Patwardhan, S. V. A Feasibility Study of the Biologically Inspired Green Manufacturing of Precipitated Silica. Chem. Eng. J. 2014, 244, 483-492.

(13) Belton, D. J.; Patwardhan, S. V.; Annenkov, V. V.; Danilovtseva, E. N.; Perry, C. C. From Biosilicification to Tailored Materials: Optimizing Hydrophobic Domains and Resistance to Protonation of Polyamines. Proc. Natl. Acad. Sci. U.S.A. 2008, 105, 5963-5968.

(14) Jantschke, A.; Spinde, K.; Brunner, E. Electrostatic Interplay: The Interaction Triangle of Polyamines, Silicic Acid, and Phosphate Studied through Turbidity Measurements, Silicomolybdic Acid Test, and ${ }^{29}$ Si NMR Spectroscopy. Beilstein J. Nanotechnol. 2014, 5, 20262035.

(15) Robinson, D. B.; Rognlien, J. L.; Bauer, C. A.; Simmons, B. A. Dependence of Amine-Accelerated Silicate Condensation on Amine Structure. J. Mater. Chem. 2007, 17, 2113.

(16) Babonneau, F.; Baccile, N.; Laurent, G.; Maquet, J.; Azaïs, T.; Gervais, C.; Bonhomme, C. Solid-State Nuclear Magnetic Resonance: A Valuable Tool to Explore Organic-Inorganic Interfaces in SilicaBased Hybrid Materials. C. R. Chim. 2010, 13, 58-68.

(17) Rimola, A.; Costa, D.; Sodupe, M.; Lambert, J.-F.; Ugliengo, P. Silica Surface Features and Their Role in the Adsorption of Biomolecules: Computational Modeling and Experiments. Chem. Rev. 2013, 113, 4216-4313.

(18) Ravera, E.; Martelli, T.; Geiger, Y.; Fragai, M.; Goobes, G.; Luchinat, C. Biosilica and Bioinspired Silica Studied by Solid-State NMR. Coord. Chem. Rev. 2016, 327-328, 110-122.

(19) Emami, F. S.; Puddu, V.; Berry, R. J.; Varshney, V.; Patwardhan, S. V.; Perry, C. C.; Heinz, H. Prediction of Specific Biomolecule Adsorption on Silica Surfaces as a Function of $\mathrm{pH}$ and Particle Size. Chem. Mater. 2014, 26, 5725-5734.

(20) Heinz, H.; Pramanik, C.; Heinz, O.; Ding, Y.; Mishra, R. K.; Marchon, D.; Flatt, R. J.; Estrela-Lopis, I.; Llop, J.; Moya, S.; et al. Nanoparticle Decoration with Surfactants: Molecular Interactions, Assembly, and Applications. Surf. Sci. Rep. 2017, 72, 1-58.

(21) Jorge, M.; Milne, A. W.; Sobek, O. N.; Centi, A.; PérezSánchez, G.; Gomes, J. R. B. Modelling the Self-Assembly of SilicaBased Mesoporous Materials. Mol. Simul. 2018, 44, 435-452. 
(22) Baccile, N.; Laurent, G.; Bonhomme, C.; Innocenzi, P.; Babonneau, F. Solid-State NMR Characterization of the Surfactantsilica Interface in Templated Silicas: Acidic versus Basic Conditions. Chem. Mater. 2007, 19, 1343-1354.

(23) Tanev, P. T.; Pinnavaia, T. J. Mesoporous Silica Molecular Sieves Prepared by Ionic and Neutral Surfactant Templating: A Comparison of Physical Properties. Chem. Mater. 1996, 8, 20682079.

(24) Centi, A.; Manning, J. R. H.; Srivastava, V.; Van Meurs, S.; Patwardhan, S. V.; Jorge, M. The Role of Charge-Matching in Nanoporous Materials Formation. Mater. Horiz. 2019, 6, 1027-1033.

(25) Spinde, K.; Pachis, K.; Antonakaki, I.; Paasch, S.; Brunner, E.; Demadis, K. D. Influence of Polyamines and Related Macromolecules on Silicic Acid Polycondensation: Relevance to "Soluble Silicon Pools"? Chem. Mater. 2011, 23, 4676-4687.

(26) Brückner, S. I.; Donets, S.; Dianat, A.; Bobeth, M.; Gutiérrez, R.; Cuniberti, G.; Brunner, E. Probing Silica-Biomolecule Interactions by Solid-State NMR and Molecular Dynamics Simulations. Langmuir 2016, 32, 11698-11705.

(27) Montagna, M.; Brückner, S. I.; Dianat, A.; Gutierrez, R.; Daus, F.; Geyer, A.; Brunner, E.; Cuniberti, G. Interactions of Long-Chain Polyamines with Silica Studied by Molecular Dynamics Simulations and Solid-State NMR Spectroscopy. Langmuir 2020, 36, 1160011609 .

(28) Wisser, D.; Brückner, S. I.; Wisser, F. M.; Althoff-Ospelt, G.; Getzschmann, J.; Kaskel, S.; Brunner, E. 1H-13C-29Si Triple Resonance and REDOR Solid-State NMR - A Tool to Study Interactions between Biosilica and Organic Molecules in Diatom Cell Walls. Solid State Nucl. Magn. Reson. 2015, 66-67, 33-39.

(29) Lutz, H.; Jaeger, V.; Schmüser, L.; Bonn, M.; Pfaendtner, J.; Weidner, T. The Structure of the Diatom Silaffin Peptide R5 within Freestanding Two-Dimensional Biosilica Sheets. Angew. Chem., Int. Ed. 2017, 56, 8277-8280.

(30) Roehrich, A.; Drobny, G. Solid-State NMR Studies of Biomineralization Peptides and Proteins. Acc. Chem. Res. 2013, 46, 2136-2144.

(31) Abacilar, M.; Daus, F.; Haas, C.; Brückner, S. I.; Brunner, E.; Geyer, A. Synthesis and NMR Analysis of $13 \mathrm{C}$ and $15 \mathrm{~N}$-Labeled Long-Chain Polyamines (LCPAs). RSC Adv. 2016, 6, 93343-93348.

(32) Ben Shir, I.; Kababya, S.; Schmidt, A. Binding Specificity of Amino Acids to Amorphous Silica Surfaces: Solid-State NMR of Glycine on SBA-15. J. Phys. Chem. C 2012, 116, 9691-9702.

(33) Geiger, Y.; Gottlieb, H. E.; Akbey, Ü.; Oschkinat, H.; Goobes, G. Studying the Conformation of a Silaffin-Derived Pentalysine Peptide Embedded in Bioinspired Silica Using Solution and Dynamic Nuclear Polarization Magic-Angle Spinning NMR. J. Am. Chem. Soc. 2016, 138, 5561-5567.

(34) Folliet, N.; Gervais, C.; Costa, D.; Laurent, G.; Babonneau, F.; Stievano, L.; Lambert, J.-F.; Tielens, F. A Molecular Picture of the Adsorption of Glycine in Mesoporous Silica through NMR Experiments Combined with DFT-D Calculations. J. Phys. Chem. C 2013, 117, 4104-4114.

(35) Manning, J. R. H.; Yip, T. W. S.; Centi, A.; Jorge, M.; Patwardhan, S. V. An Eco-Friendly, Tunable and Scalable Method for Producing Porous Functional Nanomaterials Designed Using Molecular Interactions. ChemSusChem 2017, 10, 1683-1691.

(36) Heinz, H. Clay Minerals for Nanocomposites and Biotechnology: Surface Modification, Dynamics and Responses to Stimuli. Clay Miner. 2012, 47, 205-230.

(37) Heinz, H.; Vaia, R. A.; Krishnamoorti, R.; Farmer, B. L. SelfAssembly of Alkylammonium Chains on Montmorillonite: Effect of Chain Length, Head Group Structure, and Cation Exchange Capacity. Chem. Mater. 2007, 19, 59-68.

(38) Manning, J. R. H.; Routoula, E.; Patwardhan, S. V. Preparation of Functional Silica Using a Bioinspired Method. J. Vis. Exp. 2018, $138,57730$.

(39) Massiot, D.; Fayon, F.; Capron, M.; King, I.; Le Calvé, S.; Alonso, B.; Durand, J.-O.; Bujoli, B.; Gan, Z.; Hoatson, G. Modelling
One- and Two-Dimensional Solid-State NMR Spectra. Magn. Reson. Chem. 2002, 40, 70-76.

(40) Engelhardt, G.; Michel, D. High-Resolution Solid-State NMR of Silicates and Zeolites; Wiley: Chichester, 1987; pp 147-149.

(41) Muñoz-Aguado, M.-J.; Gregorkiewitz, M. Sol-Gel Synthesis of Microporous Amorphous Silica from Purely Inorganic Precursors. J. Colloid Interface Sci. 1997, 185, 459-465.

(42) W.R. Grace \& Company. Silicas for the Food Industry: Columbia, MD, USA, 2006.

(43) Unger, K. K.; Lork, K. D.; Pfleiderer, B.; Albert, K.; Bayer, E. Impact of Acidic/Hydrothermal Treatment on Pore Structural and Chromatographic Properties of Porous Silicas. I. The Conventional Approach. J. Chromatogr. A 1991, 556, 395-406.

(44) Patwardhan, S. V.; Tilburey, G. E.; Perry, C. C. Interactions of Amines with Silicon Species in Undersaturated Solutions Leads to Dissolution and/or Precipitation of Silica. Langmuir 2011, 27, 15135-15145.

(45) Chen, C.-Y.; Xiao, S.-Q.; Davis, M. E. Studies on Ordered Mesoporous Materials III. Comparison of MCM-41 to Mesoporous Materials Derived from Kanemite. Microporous Mater. 1995, 4, 1-20.

(46) Iler, R. K. The Chemistry of Silica: Solubility, Polymerization, Colloid and Surface Properties, and Biochemistry; A Wiley-Interscience Publication; Wiley, 1979; p 40.

(47) Grünberg, B.; Emmler, T.; Gedat, E.; Shenderovich, I.; Findenegg, G. H.; Limbach, H.-H.; Buntkowsky, G. Hydrogen Bonding of Water Confined in Mesoporous Silica MCM-41 and SBA-15 Studied by $1 \mathrm{H}$ Solid-State NMR. Chem.-Eur. J. 2004, 10, 5689-5696.

(48) Van Aelst, J.; Haouas, M.; Gobechiya, E.; Houthoofd, K.; Philippaerts, A.; Sree, S. P.; Kirschhock, C. E. A.; Jacobs, P.; Martens, J. A.; Sels, B. F.; et al. Hierarchization of USY Zeolite by NH4OH. A Postsynthetic Process Investigated by NMR and XRD. J. Phys. Chem. C 2014, 118, 22573-22582.

(49) Belton, D. J.; Patwardhan, S. V.; Perry, C. C. Spermine, Spermidine and Their Analogues Generate Tailored Silicas. J. Mater. Chem. 2005, 15, 4629.

(50) Patwardhan, S. V.; Emami, F. S.; Berry, R. J.; Jones, S. E.; Naik, R. R.; Deschaume, O.; Heinz, H.; Perry, C. C. Chemistry of Aqueous Silica Nanoparticle Surfaces and the Mechanism of Selective Peptide Adsorption. J. Am. Chem. Soc. 2012, 134, 6244-6256.

(51) Delak, K. M.; Sahai, N. Mechanisms of Amine-Catalyzed Organosilicate Hydrolysis at Circum-Neutral PH. J. Phys. Chem. B 2006, 110, 17819-17829.

(52) Belton, D. J.; Deschaume, O.; Perry, C. C. An Overview of the Fundamentals of the Chemistry of Silica with Relevance to Biosilicification and Technological Advances. FEBS J. 2012, 279, $1710-1720$

(53) Iler, R. K. The Chemistry of Silica: Solubility, Polymerization, Colloid and Surface Properties and Biochemistry of Silica; A WileyInterscience Publication; Wiley, 1979; pp 182-185.

(54) Jiang, C.; Su, A.; Li, X.; Zhou, T.; He, D. Study on the Hydrothermal Stability of MCM-41 via Secondary Restructure. Powder Technol. 2012, 221, 371-374.

(55) Müller, W. E. G.; Wang, X.; Burghard, Z.; Bill, J.; Krasko, A.; Boreiko, A.; Schloßmacher, U.; Schröder, H. C.; Wiens, M. BioSintering Processes in Hexactinellid Sponges: Fusion of Bio-Silica in Giant Basal Spicules from Monorhaphis Chuni. J. Struct. Biol. 2009, $168,548-561$.

(56) Wang, X.; Wiens, M.; Schloßmacher, U.; Jochum, K. P.; Schröder, H. C.; Müller, W. E. G. Bio-Sintering/Bio-Fusion of Silica in Sponge Spicules. Adv. Eng. Mater. 2012, 14, B4-B12.

(57) Patwardhan, S. V. Biomimetic and Bioinspired Silica: Recent Developments and Applications. Chem. Commun. 2011, 47, 75677582.

(58) Manning, J. R. H.; Brambila Renteria, C. M.; Patwardhan, S. V. Unified mechanistic interpretation of amine-assisted silica synthesis methods to enable design of more complex materials. Mol. Syst. Des. Eng. 2021, DOI: 10.1039/d0me00131g. 